\title{
MARGO GLANTZ: JUDÍA, MEXICANA Y RUSA
}

\author{
Juana Lorena Campos \\ Prof. Centro de Estudios Judaicos. \\ vani(a)uchile.cl
}

\begin{abstract}
RESUMEN
El estudio es una propuesta de lectura de la novela Las genealogias de la escritora mexicana Margo Glantz. Margo declara su sentimiento de niña expósita y judia errante a domicilio, por lo cual construye un territorio texiual que la acoge y cobija. Será la escritura de la novela un intento por entender y superar la condición de desdomiciliada.
\end{abstract}

Palabras Clave: Margo Glantz, Literatura judía, Autobiografia, Judaísmo latinoamericano.

\section{ABSTRACT}

This article proposes a unique view of the novel Las genealogias by the Mexican author Margo Glantz. In the novel Ms. Glantz describes her feelings of being an orphan and a wandering Jew, and because of this she has constructed a welcoming textual territory of acceptance. This territory will be the space of understanding and overcoming the condition of homelessness.

KEY WoRDs: Margo Glantz, Jewish Literature, Autobiography, Latin american Judaism.

\section{ANTECEDENTES DEL LIBRO}

Las genealogias es la novela más importante de la escritora mexicana Margo Glantz. Editada por primera vez en 1981, reeditada con correcciones en 1987, en 1990, en 1997 y vuelta a editar con más fotografias familiares en 2006 por la editorial Pre-Textos. Esta novela ganó el premio Magda Donato en 1982 y existe un variado número de estudios críticos sobre ella.

Tanto la vida de escritora de Margo Glantz como la vida académica han sido fructíferas y cuenta con el amplio reconocimiento de sus pares. Entre sus obras literarias se encuentran: Las genealogias (1981), El rastro (2002), Zona de derrumbe (2001), Historia de una mujer que caminó por la vida con zapatos de diseñador (2005), entre otras. Entre sus ensayos críticos encontramos: Intervención y pretexto (1981), Erosiones (1984), La lengua en la mano (1993), Esguince de cintura (1994), La Malinche, sus padres y sus hijos (2001) y Borrones y borradores (2002), entre otros escritos. Su desempeño como profesora de la Universidad Nacional Autónoma 
de México y otras universidades en el mundo la ha impulsado en su producción ensayística, donde se destacan los estudios en tomo à la figura de Sor Juana Inés de la Cruz.

Margarita Glantz es hija de la inmigración. Sus padres, un matrimonio ucraniano-judí, emigraron a México huyendo de los progromos de Rusia e intentando llegar a Estados Unidos donde no pudieron entrar porque las cuotas de inmigrantes ya estaban llenas. Margo nació en México en 1930 y su niñez estuvo marcada por los constantes cambios de casa, lo cual la hace identificarse como una "judía errante a domicilio".

Su familia se desarrolló en el seno del ruso, el hebreo, el ídish y el español, y aun cuando Margo declare no ser buena para los idiomas, el sello cultural de estas lenguas se aprecia en su novela autobiográfica Las genealogias.

El interés literario del padre de Margo Glantz es una de las herencias más determinantes en la vida de la escritora; de allí que Jacobo Glantz sea uno de los personajes centrales de Las genealogias y su fotografía sea la más recurrente dentro del álbum de fotos que exhibe el libro. Además, la escritura será uno de los motivos más significativos en la obra literaria y ensayística de la autora. Otros motivos en torno a los cuales giran las inquietudes de Margo Glantz son el sujeto femenino, el cuerpo y el viaje, motivos todos que se aprecian en Las genealogías.

La totalidad de su obra ha sido tan celebrada, que la Biblioteca Virtual Miguel de Cervantes ha dedicado un portal exclusivo donde se exhiben los trabajos de la autora y los estudios críticos de otros autores en torno a esta relevante figura? ${ }^{2}$.

Existe consenso entre los críticos en que el viaje, la memoria y el cobijo en la escritura son los temas fundamentales de la novela, que si bien se plantea como una novela inicialmente de fácil lectura, guarda una complejidad en el sentido profundo pues se encuentran la cultura judía de comidas, recuerdos y escucha, con la cultura latinoamericana de saberes populares, cuerpo y escritura.

\section{ASPECTOS FICCIONALES}

Esta novela autobiográfica se estructura a partir de un prólogo, setenta y cuatro capítulos designados con números romanos y una suerte de epílogo titulado La (su) nave de los inmigrantes. Los capítulos en su gran mayoría son conversaciones de Margo Glantz con su padre y su madre en un ambiente distendido de comidas y recuerdos acerca de la historia de la inmigración de Rusia a México y la vida que experimentaron en la nueva tierra. Los otros capitulos son integramente reflexiones de Margo respecto a lo vivido. 
El texto de la novela está enriquecido con fotos del álbum familiar, especialmente con fotografias del padre de Margo. Estas fotos no son comentadas en el texto.

El sujeto que tiene la palabra es Margo Glantz quien reiteradamente la cede a sus padres para que contesten sus dudas acerca de la vida inmigrante de la familia. A partir de las conversaciones se va develando el discurso de un yo que se reconoce en las palabras de los otros y se constituye como un ser con una historia propia.

Las genealogias tratan sobre el descubrimiento del yo mismo del sujeto que escribe.

\subsection{GRABACIÓN Y ESCRITURA DEL RECUERdo}

Cincuenta y dos de los setenta y cuatro capítulos de la novela son conversaciones de Margo con sus padres Jacobo y Lucía. Estas conversaciones fueron grabadas por Margo en un intento de fijar el recuerdo como ella misma lo expresa: "Prendo la grabadora (con todos los agravantes, asegura mi padre) e inicio una grabación histórica, $\mathrm{o}$ al menos me lo parece y a algunos amigos. Quizá fije el recuerdo" (Glantz 2006, p. 21).

Su intento por grabar se halla limitado al momento de grabar las emociones: "La nostalgia ahora es muy fuerte; lamento no poder grabar las miradas" (Glantz 2006, p. 73). Sin embargo, utiliza los entre paréntesis para poder entregar a través de la escritura los momentos emotivos. Margo transcribe desde su grabadora las voces de sus padres y en este proceso cree olvidar quién dice qué: "La conversación es de sobremesa y la comida ha sido familiar. Los diálogos van y vienen de quién sabe qué bocas. Los transcribo" (Glantz 2006, p. 138). Su proceso de escritura se basa en la trascripción de las conversaciones grabadas, pero no son solo voces, son también sonidos de la comida familiar en torno a la cual se producen las conversaciones: “( ...) y por primera vez se reúnen en un solo espacio los peces y los panes, la poesía y la cafetería, el ruido de cucharas junto a las palabras, palabras que ahora resuenan en la grabadora recordando a Chéjov, las frases sin unir, disparando los monólogos" (Glantz 2006, p. 153). Si bien es la grabación de las conversaciones familiares la base de la novela de Margo Glantz, estas conversaciones son dirigidas por ella. Margo es quien hace las preguntas y quien dirige el diálogo: "-Espérate un poquito mamá, papá está recordando cosas que antes nunca me habia contado. Vamos a oírlo" (Glantz 2006, p. 47). Además de dirigir el diálogo, lo estimula, lo inquiere, lo hace continuar:

“- ¿Te acuerdas de tu papá?

- Era buena gente.

- ¿Qué más?

- Pobre

- Pero, ¿qué más?

- Pobre. Tenía dos caballos (...) y en la puerta un letrero que decía EMPUJE

$-i$ En yidish?

-En yidish.

-¿Qué más?

$-¿$ Qué más? 
-Sí, ¿qué más?

$-. . . "$

(Glantz 2006, p. 29-30)

Margo no solo dialoga con sus padres, también los entrevista, los interroga acerca de su infancia y juventud en un intento de reconstruir el pasado.

La transcripción de las grabaciones no es mecánica. Margo elige los trozos y comenta algunos dichos, partes de los diálogos las transcribe y otras partes las narra, de esta manera va construyendo la imagen de un pasado que moldeó a su familia de una forma única con recuerdos de Rusia y amor por México. Sin embargo, el recuerdo se confunde y no hay claridad sobre la minuciosidad del dato.

Es la escritura la que fija el recuerdo caótico, desordenado, impreciso. En la escritura, el pasado cobra forma y en un intento por rescatarlo, Margo debe acudir a variadas estrategias: "Aquí entra mi recuerdo, es un recuerdo falso, es de Bábel. Muchas veces tengo que acudir a ciertos autores para imaginarme lo que mis padres recuerdan" ( Glantz 2006, p. 36).

La imaginación del recuerdo es el paso necesario que debe dar Margo como un antecedente del momento de escribir, es decir, que la narradora procesa e interpreta toda la información que recibe y luego escribe. La corrección del recuerdo no es solo tarea de la narradora; entre los padres también ocurre una suerte de corrección y completación de lo que el otro está contando.

El recuerdo es colectivo, pero sin duda son los recuerdos del padre los más recurrentes en la novela: "Mis padres discuten mucho y la conversación se vuelve un diálogo de sordos (...) recojo pedazos de conversación" (Glantz 2006, p. 57).

Los diálogos de Margo con sus padres llegan en algunas ocasiones a tener un tono inquisitivo, pues la narradora está ávida por el pasado, ante esto los padres reaccionan impacientes:

"- (...) teníamos que ponernos (..) un moño de terciopelo verde y alrededor del sombrero una cinta ancha verde claro, adelante un moño.

- ¿Verde limón o verde nilo?

- Verde, verde, oscuro, bonito, bueno, verde. ¿Qué importa? ¡Ay, Margo! (...)” (Glantz 2006, p. 43).

La avidez por condensar el recuerdo para plasmarlo en la escritura es un motivo que la narradora repite a lo largo de la novela:

"Repetir un acto mil veces condensa el recuerdo, pero los recuerdos traicionan aunque se recuerde mil veces en la mente. Jacobo niega ciertas minucias que antes recordaba (...) Mi padre dice que cada vez recuerda mejor las cosas de su infancia y que casi todo lo demás se borra: a veces resucita y yo lo aprovecho como buitre"

(Glantz 2006, p. 99-100). 
Para la narradora cualquier indicio del pasado es materia para su novela. Inclusive las recetas de cocina son materia de interrogatorio, grabación y transcripción como se aprecia en el capitulo XLIIl donde Margo pregunta cómo se cocina el gefilte fish, el jolodietz, los vareniques y los gribelaj pues "Sin cocina no hay pueblo" (Glantz 2006, p. 132).

\subsection{ReFLEXIONES}

A partir de los recuerdos de los padres, la escritura muestra a un sujeto: Margo, llena de variadas reflexiones sobre la vida, su ser mujer, el viaje errante que le tocó por suerte, las comidas, las lenguas, la vida de los inmigrantes en México, etc. Margo es la narradora de la novela y el sujeto fundamental del cual se habla. De hecho, los últimos veintiún capítulos de la novela, de un total de los setenta y cuatro, están íntegramente destinados a los recuerdos y reflexiones de la propia Margo Glantz.

La reflexión más recurrente en tomo a la cual gira el relato es la memoria: "La memoria se desplaza, se subordina al olvido, se liga a la identidad y todo da vueltas" (Glantz 2006, p. 153) Gracias a ella es posible reconstruir las genealogías que requiere para no sentirse niña expósita. La memoria es un esfuerzo estimulado por el proceso de la escritura: "(...) nombres que recién empiezo a desenmarañar y a ordenar en mi cabeza a medida que redacto estas páginas" (Glantz 2006, p. 121). Hacer memoria es un proceso lento, reflexivo: "Me detengo: miro alrededor y observo esta galería de cuadros de una exposición en que se ha convertido mi relato y enseguida asoman otras figuras de los labios de mi padre" (Glantz 2006, p. 128).

La memoria sustenta el relato de Margo, por lo cual indagar reflexivamente sobre ella es una necesidad de la escritora: "Dicen que la memoria "se porta a sí misma" y quizás esto se aplique también a los olvidos. Quizás haya memorias repetidas, contadas en la mente de cinco o seis maneras, apenas con variantes (...)" (Glantz 2006, p. 151-152).

Otro tema de constante reflexión es ella misma. Se describe como una mujer con una familia muy sólida y cariñosa, con un gran gusto por la comida, mala para los idiomas: "Mascullo el inglés, medio hablo el francés y apenas entiendo el yidish coloquial; del hebreo mal conozco las letras" (Glantz 2006, p. 175). Con un cuerpo envejecido con dignidad, con la manía de la escritura y con el rechazo de su nombre de flor: Margarita. "A mí nunca me gustó mi nombre" (Glantz 2006, p. 155) Y asume el nombre cantado en un tango: Margo.

Margo reflexiona sobre su vínculo con Argentina, sobre sus simpatías con Colón, sobre el jazz, sobre su infancia errática de domicilio en domicilio, sobre sus lecturas, sobre su autoimagen y lo complejo de encontrar parejas para el baile en su juventud, sobre José Emilio Pacheco, sobre los viajes, sobre el movimiento juvenil sionista de sus años de adolescente, sobre el cine, sobre escritores rusos y latinoamericanos, sobre su paso por el cristianismo, sobre su viaje a Rusia y sobre la escritura de sus genealogías. A cada uno de estos temas dedica un capitulo entero. 


\subsection{EL SABOR DEL RECUERDO}

Otro tema constante a lo largo de la novela es la comida. La comida se vuelve un eco de las palabras del recuerdo. Cada diálogo con sus padres es en tomo a una mesa donde se sirve la comida preparada por la madre. El inicio del primer capítulo donde prende la grabadora para empezar su grabación se sitúa en un ambiente de comida: "Prendo la grabadora (...) Mi madre me ofrece blintzes (crepas) con crema (el queso lo hace sobre todo ahora que ya no tiene un restaurant que atender (...)" (Glantz 2006, p. 21).

De esta manera continúa el resto del relato, nunca se dice en qué ciudad o casa están conversando, pero cada diálogo está situado entre platillos que Margo explicita con atención: "Se oye el ruido de los cubiertos sobre el plato de blintzes, sobre los vasos de cristal de pepita (y los portavasos de plata), mi padre le echa cinco cucharaditas de azúcar al té y yo aprovecho para insistir: - ¿De dónde más traían cosas?" (Glantz 2006, p. 23).

Todo el proceso en torno a la mesa es anotado por Margo: "Mamá lava los platos en la cocina, luego viene y nos pide que pasemos a la mesa, está sirviendo el té. Vamos allí y mi papá prosigue entusiasmado." (Glaniz 2006, p. 47).

El relato principal del recuerdo está en manos del padre, pero el relato sensorial de la tradición familiar se sitúa en la comida que prepara la madre y el ruido de los elementos de la mesa: vasos, cucharas y risas.

Cada vez que un diálogo reposa, la narradora ubica su punto de grabación en la comida: "Nos detenemos un momento. Mamá sirve sopa con tallarines, comemos, descansamos, luego sirve ternera fría con ensalada de betabeles, por fin, un postre, una especie de strudl con té, muy caliente" (Glantz 2006, p. 69).

Los padres de Margo tuvieron una panaderia y un restaurant, además de una zapatería, llamado "Carmel" donde giró la vida cultural de su círculo de amigos. Desde ese entonces la conversación en torno a una mesa se hizo una costumbre que nunca se olvidó, por lo cual transcribir los momentos de la comida son también una forma de avivar el recuerdo y la memoria de la familia.

Para Margo la comida también es un elemento personal que evidencia un par de veces de manera irónica: "Pero Margo, ¿por qué no comes? No has comido nada (Nada, sólo ternera fría, pecho de res, kasha, tallarines, puré de papá, ensalada de frutas, pasteles, strudls y luego, más tarde, té con otros strudls. A mamá le parece que estoy muy delgada" (Glantz 2006, p. 72).

Los relatos de la madre también son rescatados por la narradora y muchos de ello dicen relación con los alimentos.

En los capítulos en los cuales se transcriben conversaciones con los padres está mucho más presente la comida que en los capitulos donde Margo reflexiona sobre sus ideas, sin embargo el capitulo de reflexión XLIII está íntegramente destinado a recetas de platos recordados por 
Margo. Ella dice en este capítulo: "casi puedo decir que por mis venas corre harina (...) No lloro, nomás me acuerdo" (Glantz 2006, p. 132).

La comida se configura en un elemento cotidiano que atrae el pasado a la mesa y a la conversación que se graba y ayuda a reestablecer la genealogía de la narradora. Mientras el padre relata, la madre relata y cocina y este conjunto le entrega a Margo un recuerdo más integro que aquel solo hecho de palabras.

\subsection{Margo Judia}

Margo Glantz es apelada por su nombre en el texto y ella misma reflexiona sobre este hecho por lo cual la identidad de la narradora no es un misterio. Margo escribe sus genealogías y en este intento escribe sobre ella misma. Escribe desde su adultez recordando su infancia y juventud, escribe desde la mesa familiar que durante años albergó sabores y recuerdos, escribe desde su condición de judia aunque no lo parezca: "Y todo es mio y no lo es y parezco judía y no lo parezco (...)" (Glantz 2006, p. 19).

La escritura le da un lugar en el mundo, lugar que puede ser incómodo para los demás: "Mientras escribo, entra Renata a mi despacho y dice, furiosa:-Mamá, en esta casa la única alegría es la máquina de escribir" (Glantz 2006, p. 211).

Su condición de judía hace de esta escritura algo especial. Desde el prólogo se define como parte del judaísmo:

"Quizá lo que más me atraiga de mi pasado y de mi presente judio sea la conciencia de los colorines, de lo abigarrado, de lo grotesco, esa conciencia que hace de los judíos verdaderos gente menor con un sentido del humor mayor, por su crueldad simple, su desventurada ternura y hasta por su ocasional sinvergonzonería. Me atraen esas viejas fotografias de un abonero lituano, con su barba puntiaguda (propicia a las persecuciones) y su abrigo desmesurado (...) También me atraen esos niños de jeider (escuela judía) que van acompañando a un abuelo con la mirada gastada y la barba blanca, pero no les pertenezco, apenas desde una parte aletargada de mí misma,(...)" (Glantz 2006, p. 16).

Declara no haber tenido una infancia religiosa, poner árbol de navidad y haberse casado con un no judío, sin embargo, su sentimiento de niña expósita la hace reconocerse como parte del pueblo escogido. Es fundamentalmente la experiencia del exilio de sí misma lo que la hace sentirse judía. Esta condición no es tácil: "Los judios son llorones y las judías aún más" (Glantz 2006, p. 189); "(...) yo, con los antecedentes masoquistas del pueblo elegido, no quisiera verme fea" (Glantz 2006, p. 188); "La palabra judio es fuerte, casi parece una blasfemia mentada (...)" (Glaniz 2006, p. 205). Declararse judía no es sencillo, es asumir la historia errante del pueblo y entender que el sentimiento de desdomiciliada la acompañará por siempre.

“(...) y yo judia y mexicana y rusa, sobre todo mexicana de la calle Jesús Maria" (189). Margo se presenta a si misma primeramente como judía, luego como mexicana y finalmente como rusa, también encontramos: "(...) pero quiero asegurarles que no soy tan vieja, que solo soy judia (...)" (Glantz 2006, p. 161). 
En cada una de estas definiciones se subentiende su condición de mujer, mujer judía. Esto implica llanto: “(...) nosotras lloramos por contaminación, por tristeza ancestral y por nuestra vieja condición de cebollas" (Glantz 2006, p. 191).

\subsection{SIGUIENDO LOS PASOS DEL PADRE}

Margo se reconoce como una seguidora de los pasos de su padre, tanto por su inclinación a las letras como por su capacidad viajera: "(...) he seguido como Telémaco las de Ulises, las huellas de mi padre" (Glantz 2006, p. 163). El padre viajó inicialmente para huir de los progromos y luego como parte de su trabajo, Margo viaja para encontrar sus genealogías:

“(...) en esta concienzuda y también desmelenada búsqueda de raíces (suena apantallante), enfilé hacia la Europa Oriental, cuna de mis antepasados por parte de padre y por parte de madre. Sí, fui a Rusia para convertirme en la primera persona de la familia (mexicana) en rehacer el trayecto para repasar las huellas que mis padres dejaron (1925) antes del viaje hacia México, cuando abandonaron, para siempre, la tierra de sus antepasados (...)" (Glantz 2006, p. 203).

El viaje que sufre Margo es por paises, pero también por domicilios:

"Mi infancia, la verdadera, transcurrió completa durante la presidencia del general Cárdenas. Viví por muy distintos barrios y los traslados de uno a otro trastornaban mi vida escolar. (...) fui rodando, como la Santa de Gamboa de barrio en barrio, de escuela en escuela; a veces no llegué a permanecer más de dos o tres meses, con el resultado de que me volví autista" (Glantz 2006, p. 168-169).

Su condición viajera la hereda de su familia y la inspira su familia, sus padres, sus abuelos. La narradora se considera Colón realizando un viaje descubridor, se reconoce emprendiendo un viaje "mujer afuera" que la lleva a conocer aspectos desconocidos de sí misma. Escribir para Margo también es un tipo de viaje al pasado que la hace entender su presente, pues recuerda hechos ya olvidados " $(. .$.$) recién empiezo a desenmarañar y a ordenar en mi cabeza a medida que$ redacto estas páginas" (Glantz 2006, p. 121) Escribir la hace conocerse a si misma y a su entorno, vislumbrar su pasado y acceder al futuro. El destino viajero que la narradora dice tener parte con los cambios de domicilio, sigue con el viaje a Rusia y culmina en su proceso escritural, de esta manera, escribir sobre sus innumerables viajes es viajar.

El padre de Margo es el impulsor de este proceso viajero: "(...) yo sabía que mi destino era viajero, casi como el de Telémaco, que recorrió el universo al revés en busca de la fama de su padre" (Glantz 2006, p. 178).

El padre de Margo, Jacobo Glantz, murió en 1982, un año después de la primera edición de este libro, y en las posteriores ediciones Margo indica su fallecimiento. Para la narradora él es el verdadero Colón que cruza océanos para descubrir tierras nuevas. La figura del padre impulsa el viaje de Margo. Él no solo ha incursionado en lo geográfico y en la historia sino también en las artes y la literatura. Jacobo fue un escritor que mantuvo fuertes relaciones sociales con el grupo artístico de su tiempo en México, conoció a Diego Rivera quien quiso retratarlo y a un sinnúmero de artistas locales y rusos. Escribió fundamentalmente poesía, una de las cuales 
dedicada a Cristóbal Colón, pues ésta es una figura relevante en la expulsión de los judíos de España en 1492. Como se aprecia, el interés por Colón lo hereda la narradora.

\subsection{Fotografias}

El libro en su edición de 2006 exhibe un total de veinticinco fotos, más la portada de un libro de Chagall. Una foto en la dedicatoria, otra en el prólogo y las restantes en el transcurso de los capítulos. Las fotos no son comentadas, pero sí tituladas. Están colocadas según el tema que se está narrando. Se destaca la gran cantidad de fotos del padre, en solitario aparecen cinco fotos y otras cuantas en compañía de la familia. Las fotos del padre lo retratan como mexicano, poeta, melancólico y escultor; ningún otro miembro de la familia es tan definido como él. El segundo grupo de fotos más recurrente es la foto de ambos padres, que van indicando el paso del tiempo.

Abundan las fotos de grupos por sobre las individuales. Se exhiben fotos de los abuelos, los tios, los padres, las hermanas, los nietos, las hijas y la propia Margo.

La primera foto que exhibe el capítulo I es de Jacobo Glantz mexicanizado. De esta manera, las genealogías de Margo presentan al padre como punto de partida del libro. La última foto pertenece a las hijas de Margo, Alina y Renata, el porvenir.

Las fotos iniciales del libro corresponden a los padres, abuelos y tíos; las fotos finales, a hijas y nietos. A través de la revisión del álbum de fotos que muestra el libro se observa el paso del tiempo y la genealogía familiar de la escritora de manera detallada y cuidadosa. Es un discurso visual que corre paralelo el discurso verbal de la novela.

La única imagen que presenta el libro, que no es una fotografia, corresponde a la portada del libro de Marc Chagall editado en sueco, Mitt liv. La primera edición de este libro fue en ruso, $M a$ vie en 1931. Este libro es una autobiografía del pintor ruso judío quien también experimentó la vida de inmigrante. Margo Glantz ha conservado esta imagen seguramente porque el pintor evocó a lo largo de toda su vida la experiencia familiar y cotidiana de su aldea judía.

La primera edición de Las genealogias en el año 1981 y las posteriores ediciones no presentan tantas fotos como la edición del 2006; en cambio presentan una gran cantidad de documentos de inmigración que no aparecen en la úlitima edición de Pre-Textos.

\section{EL MUNDO REPRESENTADO}

\subsection{Niña EXPósIta}

En el capítulo LXIII dice la narradora:

Siempre me ha asombrado esta familiaridad que tengo con el niño expósito y nunca me la he acabado de explicar con exactitud (...) Alguien me dice que quizás todo se deba a esa sensación terrible de pertenecer al pueblo elegido o al sentimiento intenso de desolación que experimentaba cuando el 6 de enero me asomaba debajo de la cama y no encontraba ningún 
juguete, semejante a los que ostentaban (...) los niños católicos (...) Ningún regalo de Jánuka (...) bastaba para deshacer el recuerdo y la triste sensación de niña expósita que me ha atacado siempre (...)

Quizás estas genealogías me ayuden a entenderlo (Glantz 2006, p. 182-183).

El objetivo del proceso escritural de la narradora-autora es entender el sentimiento de niña expósita, de sujeto a la deriva, en definitiva, de inmigrante permanente a pesar de haber nacido y vivido en México. Margo intenta buscar la razón de su desolación en la vida de sus padres y abuelos porque indagando la vida de su familia se va construyendo un espacio de cobijo donde pueda superar la condición de expósita. Se plantea la posibilidad de que este sentimiento sea producto de la no celebración de las fiestas cristianas, pero también cree que puede deberse al sino del pueblo elegido, quien es considerado un pueblo errante.

El judaísmo, la pertenencia al pueblo errante, es un móvil de la escritura, puesto que allí se puede encontrar la razón de la desolación. Inicialmente, ella establece que la vinculación de ella misma con el judaísmo no es tan estrecha porque no sabe hebreo, no ha estudiado el Talmud y se casa con un goi (no judío), sin embargo comparte el sentimiento de emigrante eterno y debe escribir sobre una familia de este pueblo para poder comprenderse.

Esta escritura reveladora se inicia con la simple transcripción de las conversaciones que establece con sus padres, pero luego se van advirtiendo cursivas y entre paréntesis que indican que la escritura misma es materia de reflexión. Comienzan los capítulos dedicados a fijar las reflexiones personales de la narradora y el libro finaliza sin transcripciones de conversaciones sino con un lenguaje tipo ensayo, reflexivo y autocrítico. ¿Acaso el sentimiento de niña expósita ha sido superado?

Margo de niña anduvo de escuela en escuela y de casa en casa, no recibió regalos de Navidad ni de la fiesta de reyes. De adulta viajó para rehacer las huellas viajeras de sus padres y no sabe a ciencia cierta si parece o no judía. La escritura de Las genealogias le permite reconocerse como judia, mexicana y rusa. Es en la escritura donde el sujeto se configura como tal.

El ser humano tiene necesidades profundas que no siempre entiende cabalmente. La búsqueda incesante por saciar esos indescriptibles requerimientos del alma lo llevan a probar una y otra forma de satisfacción. Además, la necesidad de pertenencia del yo con el otro acentúa aún más esta búsqueda que al no ser exitosa transforma la vida en una desdicha. En este momento es cuando, más que decir algo, el puro hecho de decir permite al hombre y a la mujer comunicarse con otro y realizarse en tanto ser humano, pues el vínculo por medio de la palabra los acerca al misterio de la vida. La escritura, entonces, se nos presenta como un intento de vinculación del yo con el otro, lo cual nos da un sentido de existencia.

Margo Glantz es parte de la generación hispanoamericana del 72 reconocida por Cedomil Goić, en la cual la fragmentariedad se erige como modo de representación, superando así la binariedad y unicidad de las generaciones anteriores. La realidad se desarticula en múltiples fragmentos, como lo plantea Francisco Aguilera, y los retazos de la experiencia humana son apenas aprehendidos por los narradores de estas novelas, quienes pasan a constituirse en recolectores 
de la experiencia, es decir que la memoria y la escritura actúan como restauradora de retazos de historia y los contextualizan para integrarlos en mundos posibles. Margo Glantz elige del pasado brindado por sus padres, momentos que le permiten configurar su árbol genealógico para generar un cobijo que la salve del sentimiento de niña expósita, errante y nostálgica. La configuración de este mundo es por medio de la escritura con la cual teje un soporte para las fotos que exhibe en el libro, las cuales no dan por si mismas un cabal recuerdo del pasado. El discurso verbal arma un mundo posible que prueba que Margo es judía, mexicana y rusa gracias a las diferentes cunas que tuvo y que la moldearon de una determinada forma. Su ser mujer se aferra a la escritura para identificarse. Lo que es lo escribe y al escribirlo lo declara universalmente. Margo se escribe en el tex to y se reconoce en él como parte de tres culturas que se plasman en tres lenguas que dice no hablar, excepto el español, pero que la marcan indiscutiblemente.

\subsection{Custodia de la memoria}

Yosef Hayim Yerushalmi en su estudio Zajor: la historia judia y la memoria judia plantea que no han sido los historiadores los custodios fundamentales de la memoria en el judaismo. Que el pueblo, si bien ha estudiado acuciosamente el significado de la historia bíblica, no ha tenido el mismo interés por la historiografía a través de los tiempos. Los reales custodios son los que han recibido y trasmitido los hechos significativos del pasado:

"Cuando decimos que el pueblo "recuerda", en realidad estamos diciendo que un pasado ha sido activamente transmitido a la presente generación, y que ese pasado ha sido admitido como significativo. Y: a la inversa, un pueblo "olvida" cuando la generación que ahora posee el pasado no se lo transmite a la siguiente, o cuando ésta última rechaza lo que recibe y no lo sigue pasando a las generaciones sucesivas, lo que viene a ser lo mismo" (Yerushalmi 2002, p. 130).

En este sentido, el rol de Margo Glantz al escribir Las genealogias es ser custodia de la memoria judía, pues recibe los recuerdos de sus padres y los reelabora en un texto que publica y reedita reiteradas veces, intentando una mejor versión para los lectores. El cuidado de recepcionar el recuerdo, elaborarlo en un relato y entregarlo en un tex to es lo que hace que la memoria del pueblo judío se revitalice y permanezca:

"(...), me parece (...) la esencia de la memoria colectiva como un movimiento dual de recepción y transmisión, que sucesivamente se impulsa a sí mismo hacia el futuro. Es este proceso lo que forja la mneme del grupo, la sucesión de la memoria, que es la de los eslabones en una cadena, y no la de un hilo de seda. Los judios no fueron virtuosos de la memoria. Sin embargo, sí fueron receptores bien dispuestos y soberbios transmisores" (Yerushalmi 2002, p. 131).

Es la condición judía de Margo Glantz la que la impulsa a recepcionar eventos del pasado de sus padres y a transmitirlos generando una cadena genealógica que la cobija y sostiene.

Yerushalmi, por otro lado, plantea que la memoria judía fluye por dos canales: el ritual y el relato. El relato que elabora y transmite Glantz se instala en el ritual de las comidas, como ya lo señalé. Ana María Tapia en su libro Costumbres y tradiciones judias dice que el judaísmo comienza en la cocina, haciendo una clara referencia a los típicos menús que acompañan cada celebración y conmemoración del pueblo -recordemos que Margo declara: "sin comida no hay 
pueblo". De esta manera, la comida es un ritual propio del judaísmo que se repite al interior de Las genealogias, generando un espacio propicio para el recuerdo y la conmemoración. El relato de los recuerdos requiere elaborarse en un locus apropiado para que sea significativo. Silvia Molloy en su estudio Acto de presencia. La escritura autobiográfica en Hispanoamérica, también plantea la necesidad de un espacio estable desde donde se construya el relato del recuerdo, dice:

"Este alejarse del lugar de origen, componente decisivo de la experiencia individual del autobiógrafo hispanoamericano, debe verse en conjunción con un sentido muy particular de la historia, el que lleva, como se ha visto, a privilegiar esas "últimas miradas" a un pasado personal en el cual se busca incorporar al lector. Tanto el alejamiento del lugar de origen como la concepción catastrófica de la historia parecen exigir al autobiógrafo la creación de un lugar común estable para la rememoración. La forma más frecuente que adopta ese lugar común es, desde luego, la casa familiar, la casona" (Molloy 1996, p. 225).

Molloy considera que el lugar estable común es la casa familiar y esto se aprecia en Las genealogias, pero dentro de la casa es la mesa familiar el lugar estable donde se construye la novela. Desde este espacio se puede mirar el lugar de origen y evocar la vida nómada que ha tenido la familia.

A la luz del judaismo, la recepción y la transmisión del pasado que realiza Margo Glantz cobra un sentido profundo en relación con la tradición judaica de todos los tiempos. Todo el pueblo judío es responsable de la transmisión del pasado. Quizás son los escritores autobiógrafos quienes se plantean como custodios de las memorias familiares contribuyendo de manera radical, fundamental y prioritaria a conservar la memoria colectiva, no ya de una familia particular, sino de todo un pueblo. Margo instaura una lucha en contra del olvido empujando el acto de recordar. A pesar de no ser religiosa realiza el mandato bíblico, puesto que cualquier judío tiene sobre sus hombros la demanda divina de recordar y no olvidar. Posiblemente de esta apelación surgen tantas autobiografías y restauraciones de genealogias y álbumes de familia. Los autobiógrafos judíos más que solo describir hechos y relaciones familiares, buscan el significado de esa historia. Margo en sus ensayos y monólogos lo hace de manera decidida; así, al igual que los rabinos se plantea como una buscadora de significado de la historia y no solo como una historiógrafa o biógrafa. Margo Glantz colabora con la mantención y resguardo de la memoria al evocar el pasado y fijarlo en la escritura.

\subsection{EL MARCO DE LA MEMORIA FAMILIAR}

Elizabeth Jelin en su libro Los trabajos de la memoria declara que la memoria es individual y social:

"Las memorias son simultáneamente individuales y sociales, ya que en la medida en que las palabras y la comunidad de discurso son colectivas, la experiencia también lo es. Las vivencias individuales no se transforman en experiencia con sentido sin la presencia de discursos culturales, y éstos son siempre colectivos. A su vez, la experiencia y la memoria individuales no existen en si, sino que se manifiestan y se tornan colectivas en el acto de compartir. O sea, la experiencia individual construye comunidad en el acto narrativo compartido, en el narrar y el escuchar" (Jelin 2002, p. 37). 
La combinación de estas memorias se aprecia con claridad en Las genealogias, donde Margo rescata su entorno social familiar como estímulo para la evocación y el recuerdo. La novela transita entre la memoria individual de Margo y la familiar, específicamente la de sus padres. El tejer de los recuerdos familiares es el punto de partida que le permite a la narradora evocar momentos de su niñez y juventud para reconocerse como un yo perteneciente a la cultura rusa-judia y mexicana. En palabras de Maurice Halbwachs, el padre de los estudios de memoria colectiva, "el marco de la memoria familiar" es el sostén del relato de Margo y solo gracias a este marco social es posible que la memoria surja y se construya como un pasado significativo. También plantea el autor que la idea de domicilio fija el individuo a la familia, ésta al hogar y el hogar al suelo. Aquí se produce un sentimiento de pertenencia, el mismo sentimiento que Glantz busca al escribir sus genealogías, puesto que en ella el domicilio no es permanente. Su calidad de "hija de inmigrantes judíos" le quita el suelo como apoyo de una identidad domiciliada y la lleva a declararse "judia errante a domicilio". La errancia en Margo Glantz es el móvil que la lleva a rescatar el álbum de fotografias familiares, a grabar las conversaciones con sus padres, a evocar el pasado y finalmente a elaborar un relato que dé cuenta de sus genealogías, Es el marco de la memoria familiar y religiosa lo que a través de milenios ha hecho de los judios un pueblo. Inclusive para los judios no religiosos es el marco familiar el que sustenta la tradición y el soporte grupal pues, como plantea Halbwachs: "Si se busca un marco de nociones que nos sirva para evocar los recuerdos de la vida doméstica, se piensa de inmediato en las relaciones de parentesco, tal como han sido definidas en cada sociedad" (Halbwachs 2004, p. 193). De esta manera el marco social que provee la familia a los autobiógrafos les permite recordar y ejercer el rol transmisor de la memoria.

Silvia Molloy, en el estudio ya citado, también atribuye a la familia un rol fundamental en el rescate de la memoria, dice:

"Que la memoria de Sarmiento, como individuo, haya adoptado la forma de reflexión genealógica - una convocación de precursores con quienes se identifica-no es casual. Desde el Inca Garcilazo, que de niño escuchaba absorto a su madre y a sus tíos evocar un compartido pasado incaico a punto de extinguirse, hasta Borges, que en la dedicatoria de sus Obras completas agradece a su madre "tu memoria y en ella la memoria de los mayores", el pasado en Hispanoamérica se ve como un asunto de familia" (Molloy 1996, p. 212).

Molloy es su estudio detallado y minucioso de la autobiografia en Hispanoamérica dice que la familia es el soporte fundamental del recuerdo del pasado. Para el autobiógrafo no rescatar el pasado y su memoria es sufrir una pérdida:

"La ampliación y el enriquecimiento de la memoria van acompañados en casi todas las autobiografias por el temor, no menos general, a experimentar pérdida. El autobiógrafo hispanoamericano se caracteriza por su fuerte vocación testimonial: no se considera meramente testigo de ese pasado amplificado, es el único testigo de una época concluida que sólo vive en su relato (...) el pasado, hasta el pasado propio, es un anacronismo, condenado a morir si no se lo rescata dando testimonio de él" (Molloy 1996, p. 216).

En este sentido Margo Glantz experimentaria la pérdida de perder el pasado de su familia, pero también la pérdida de no tener un refugio para su condición de expósita. En la novela, el rescate de la memoria cumple una función social, la de preservar los recuerdos familiares, y una 
función individual, la de tejer un soporte verbal que acoja a la narradora desdomiciliada. Entonces, la escritura de la novela salva al grupo y al sujeto del temor a la pérdida.

Jelin también comparte la pertenencia al grupo como soporte para la memoria, dice:

"La memoria tiene entonces un papel altamente significativo, como mecanismo cultural para fortalecer el sentido de pertenencia a grupos o comunidades. A menudo, especialmente en el caso de grupos oprimidos, silenciados y discriminados, la referencia a un pasado común permite construir sentimientos de autovaloración y mayor confianza en uno/a mismo/a y en el grupo" (Jelin 2002, p. 10).

Entonces, la memoria junto con revitalizarse en marcos sociales, como lo plantea Halbwachs, le da al individuo una pertenencia de grupo, afianzándolo en un domicilio social. Por esta razón, el rescate de la memoria que realiza Glantz en su novela es más que una mera exhibición de su genealogía, es tomar un lugar en el mundo, ubicarse, establecerse, construir una residencia. Elizabeth Jelin, conociendo los postulados de Halbwachs, confirma la importancia de las redes sociales en la mantención de la memoria:

"Esta relación de mutua constitución implica un vaivén: para fijar ciertos parámetros de identidad (nacional, de género, política o de otro tipo) el sujeto selecciona ciertos hitos, ciertas memorias que lo ponen en relación con los "otros". Estos parámetros que implican al mismo tiempo resaltar algunos rasgos de identificación grupal con algunos y de diferenciación con "otros" para definir los límites de la identidad, se convierten en marcos sociales para encuadrar las memorias" (Jelin 2002, p. 25).

\subsection{TERRITORIALIZACIÓN}

Glantz selecciona hitos fundamentales del pasado que le permiten establecer redes significativas para el propósito que ella quiere lograr: territorializarse. Dice en la novela:

"El territorio propio, fundamental para el judio y para cualquier emigrante, es asumido por mi madre como aquello que se aloja en una cotidianeidad que sin embargo tiene historia: sus padres, la familia, el idioma materno, el ruso, la casa patema, su barrio, las costumbres judías son la unidad, el territorio: Todo fue normal en Rusia-dice-una casa, una familia. Una familia completa con todos los detalles, pues si..." (Glantz 2006, p. 220).

Si bien la territorialización en la cotidianeidad es una idea de la madre de Margo, la novela hace eco de esa idea y representa un mundo familiar y social del día a día. La novela no presenta complejas disquisiciones sobre la memoria y el individuo, sino más bien escenas cotidianas de la evocación de un pasado amado. Sin embargo, la cotidianeidad amorosa que se evoca sufre fracturas, como dice Jelin: "Abordar la memoria involucra referirse a recuerdos y olvidos, narrativas y actos, silencios y gestos. Hay un juego de saberes, pero también hay emociones. $Y$ hay también huecos y fracturas" (Jelin 2002, p. 17). La fractura se produce en la novela por los cambios recurrentes de domicilio, de Rusia a México y en México el cambio de diferentes casas y colegios. Esta fractura que del recuerdo pasa al alma de la narradora se intenta superar con una territorialización en el texto, no ya en un lugar geográfico sino que en la escritura.

Dice la novela: 
"El esfuerzo de mi madre por reterritorializarse -horrible y significativa palabra- es su único remedio, su única arma para derrotar la historia, cuyo discurso genealógico "normal", como diria ella, cubre trescientos años engullidos con ferocidad por un pasado trágico, pero también maravilloso, la persistencia del judaísmo en la Europa Oriental. La emigración a América exige otro esfuerzo de integración mental, estar al otro lado del océano revoluciona el signo. En el nuevo territorio, el del exilio, se reacomodan las cosas, el judaísmo se reintegra a su raíz, se habla el yidish, los enemigos son amigos y el ruso sigue siendo un idioma de unión, el idioma secreto del amor y el de la convivencia con otros exiliados del antiguo y propio territorio" (Glantz 2006, p. 224).

El territorio del exilio implica una reacomodación del alma de los sujetos, cambiar los odios y los amores, reintegrarse a la vida de un nuevo modo, sin embargo el territorio del exilio no tiene en realidad residencia y Margo lo llama "la nave de los inmigrantes":

"La nave de los inmigrantes, ese territorio flotante, intermedio, favorece la conversión, inclina a la sustitución, en suma, rearticula la idea del exilio, la prepara, la dulcifica, y asegura la posibilidad de un nuevo espacio donde todo puede reacomodarse armónicamente" (Glantz 2006, p. 224).

Pero el nuevo espacio armónico no siempre se encuentra en el espacio geográfico, de hecho, plantea que sus padres se reterritorializaron en el cuerpo de su madre. Dice Margo en la última página de la novela, refiriéndose a su madre:

“Cómo pudo sobrevivir a mi padre tanto tiempo? ¿En dónde encontró su territorio? Es más que probable que su verdadero territorio, el de ella y el de mi padre, fuese su propio cuerpo, ese cuerpo finito, reducido, llagado con el que murió, ese cuerpo que alguna vez fue armónico y hermoso, ese cuerpo en el que me alojé alguna vez, ese cuerpo que me permitió ser lo que soy" (Glantz 2006, p. 226).

Los lazos de parentesco permiten fijar cierto espacio común que sostiene a los individuos. Los padres se territorializan en el cuerpo de la madre, Margo, en cambio, en la escritura. Pero la territorialización de Margo también obedece, en un primer momento, a los lazos familiares, pues es el oficio de escritor de su padre el que la inspira en el proceso escribiente gracias al cual encuentra su espacio. Silvia Molloy en Acto de presencia... reconoce la figura del mentor como prioritaria en el proceso de escritura de los autobiógrafos:

"A menudo se asocia la escena de lectura con un mentor. En algunos casos se trata de un maestro real, pero las más de las veces es una especie de guia que dirige las lecturas del niño. En el siglo XIX, el papel lo desempeña casi siempre un hombre, ya que la lectura se asocia a lo masculino y a la autoridad" (Molloy 1996, p. 30).

La imagen de un lector adulto inspiraría al niño observador a leer y escribir sus memorias en la adultez. El padre poeta y amigo de artistas rusos y mexicanos de Margo la habría inspirado para emprender un viaje a través de la escritura. Las menciones al padre escritor y poeta son recurrentes en el libro, se detallan los nombres de los poemas más famosos y las figuras referidas en los escritos. Como ya lo señalé, la fotografia de Jacobo Glantz es la más exhibida en el texto y, además, la narradora declara más de una vez haber seguido las huellas de su padre como Telémaco. En este punto vemos una clara similitud entre la autobiografia de Glantz y el resto de las 
autobiografias que describe Molloy. Entonces, es el parentesco el que permite buscar y encontrar territorios para residir. Leemos en Molloy:

"Los recuerdos se vuelven territorio, la memoria se expande y abarca toda la superficie del país, llega a ser ese país, suerte de nueva patria en la que la autobiógrafa manda, como terrateniente convertida en propietaria del pasado" (Molloy 1996, p. 215).

Y el recuerdo Margo lo vierte en un texto. Así, memoria y escritura se convierte en el territorio de una mujer con alma de niña expósita.

\section{Continúa Silvia Molloy:}

"Si bien la meta de autobiógrafo parecería ser el descubrimiento o, mejor dicho, la construcción del yo, el proceso en realidad sigue el camino inverso. La autorrepresentación es el producto final, pero es también la figura inicial que rige el desarrollo de la autobiografia. Se recrea el pasado para satisfacer las exigencias del presente: las exigencias de mi propia imagen, de la imagen que supongo otros esperan de mi, del grupo al cual pertenezco" (Molloy 1996, p. 199).

La construcción y la representación del yo en la escritura es una clara evidencia en Las genealogías. Si bien la gran mayoría de los capítulos de la novela son retazos de las conversaciones que la narradora sostuvo con sus padres, los últimos veintiún capitulos son reflexiones de Margo y alli ella es el centro indiscutible del relato. Pareciera que la novela requiere comenzar por los otros para poder acceder al yo interior. Por lo anterior, se deduce que, en Las genealogías, la memoria colectiva permite construir una memoria individual.

\subsection{Yo, Margo}

Nora Catelli en su estudio En la era de la intimidad, seguido de: El espacio autobiográfico plantea, siguiendo los postulados de Paul de Man en La autobiografía como desfiguración, que: "(...) el sentido de narrar la propia historia proviene de la necesidad de dotar de un yo, mediante el relato, a aquello que previamente carece de un yo. El yo no es así un punto de partida sino lo que resulta del relato de la propia vida (...)" (Catelli 2007, p. 226). En este sentido, Margo Glantz se constituye como tal en su relato. La escritura dota de un yo femenino, ruso-mexicano, judío y familiar al sujeto Margo: "rehago mentalmente mis genealogias, recapitulo, es hora de darles un punto, si no aparte, al menos suspensivo: ante mi contemplo mi medio siglo (...)" (Glantz 2006, p. 217). La escritura le permite a la narradora verse, encontrarse con ella misma, contemplar su vida, establecer su yo. Catelli continúa en su estudio: "(...) lo autobiográfico debe postular el juego del Yo presente en el momento de la escritura con el Yo presupuesto o imaginado en el pasado" (Catelli 2007, p. 348). De esta manera yo Margo imaginada y yo Margo narradora generan una yo Margo que solo existe en Las genealogias y que emerge del ser profundo de Margo Glantz real.

Por otro lado, existe un variado número de estudios que analizan el tema del nombre del autor en los escritos autobiográficos. Philippe Lejeune en El pacto autobiográfico y otros estudios plantea la identidad entre el narrador, el personaje y el autor: "Para que haya autobiografia ( $y$, en general, literatura íntima) es necesario que coincidan la identidad del autor, la del narrador y la del personaje" (Lejeune 1994, p. 52). Así, el nombre tendria un referente externo al texto y 
esto se entendería en el pacto de lectura autobiográfica que se espera. Sin embargo, esta postura ha tenido muchas criticas. Nora Catelli rechaza la identidad de las tres figuras que identifica Lejeune, por considerar que el autor es un elemento de la realidad concreta que no puede identificarse con elementos ficcionales. Ante esto, Elver Ramírez en su tesis doctoral El negocio de la memoria: escritura y sujeto autobiográfico en la literatura de lengua española (1970-2005) propone, como forma de salvar la discusión sobre la identidad del autor, los términos de autor real y autor textual. De esta manera, el nombre Margo al interior de Las genealogias referiria no a Margo Glantz real sino a Margo texto, una unidad imaginaria.

El nombre Margo es atendido extensamente en la novela:

"A mi nunca me gustó mi nombre. Abundan las Margaritas en la literatura nacional como lo demostró muy bien Gabriel Zaid: Margarita Gautier, Margarita Ledesma, Margarita está linda la mar... Margarita Glantz, Margarita... Tarareo la letra del tango: "Ya no sos mi Margarita, ahora te llamás Margó"... Además, cuando me dicen Margarita siento que sigue el regaño, también la lenta y progresiva mutilación de los pétalos, y la monótona letanía de si me quiere mucho, poquito, nada, y vuelta a empezar. Creo que no tolero este tipo de suspensos. La poesía de mi nombre y la de mis hermanas ha hecho que tengamos siempre líos con la justicia, $o$ por lo menos, con el registro civil, eso unido al hecho de que siempre nos registran con diez años de retraso. La pobre de Azucena -no, también de Lirio- ha sufrido la implantación de un nombre tan florido y cada vez que pasa por el proceso de inscribir su nombre en la posteridad, la posteridad se lo reclama. No creo que nadie pueda pasar a la posteridad con el inmarcesible nombre de una flor cortada en la más antigua e inocente infancia" (155).

La narradora crea su nombre pues crea su yo. El descubrimiento del nombre y de una identidad no es una tarea fä́cil pues el proceso subjetivo de autoconocimiento es arduo y no siempre se logra. Dice Catelli:

"Pero sí cabe señalar un rasgo común entre la religiosa [Sor Teresa] y las escritoras modernas de diarios (y todo tipo de géneros del yo): las condiciones en que se practicaba y se practica la escritura. En la celda, escribir era un acto que conllevaba encierro en la soledad. $Y$ en esa soledad y en ese encierro, para Teresa, acechaban los demonios. Mientras que, en la modernidad, en semejante soledad y similar encierro, no se teme aparentemente el acecho de los demonios, sino que se espera el desarrollo de la propia subjetividad. Pareciera como si casi no hubiera términos de comparación entre el encierro teresiano con Dios y los demonios y la extensión de lo intimo en la modernidad" (Catelli 2007, p. 49).

Más adelante, la autora plantea que el desarrollo de la propia subjetividad hace que el sujeto se enfrente a los demonios interiores y ese será el verdadero espacio intimo de la modernidad.

Las genealogias ha sido considerada y estudiada como modalidad de entrevista por Elver Ramírez, pero su carácter autobiográfico es mucho más determinante, por cuanto Margo es el sujeto fundamental que se reconstruye en el relato, el proceso subjetivo es el eje central de la novela. Margo texto es la creación discursiva de Margo Glantz real. Ramírez también plantea la necesidad de los otros en la creación del yo, por lo cual las entrevistas con los padres que se aprecian en la novela son un paso previo y necesario para la individualización de Margo como un yo textual. 


\section{BIBLIOGRAFÍA}

\section{CATELLI, Nora}

En la era de la intimidad, seguido de El espacio autobiográfico

Rosario, Beatriz Viterbo, 2007.

GLANTZ, Margo

Las genealogias

Valencia, Pre-Textos, 2006.

GOIĆ, Cedomil

Historia de la novela hispanoamericana

Valparaíso, Universitarias de Valparaíso, 1980.

HALBWACHS, Maurice

Los marcos sociales de la memoria

Barcelona, Anthropos Editorial; Concepción: Universidad de la Concepción

Caracas: Universidad Central de Venezuela, 2004.

JELIN, Elizabeth

Los trabajos de la memoria

Madrid, Siglo XXI de España Editores, 2002.

LEJEUNE, Philippe

El pacto autobiográfico y otros estudios

Madrid, Megazul-Endymion, 1994.

MOLLOY, Sylvia

Acto de presencia: la escritura autobiográfica en Hispanoamérica

México, D.F., El Colegio de México, 1996.

RAMÍREZ FRANCO, Elver

El negocio de la memoria: escritura y sujeto autobiográfico en la literatura de lengua española (1970-2005)

Tesis Doctoral. Ph D in Hispanic Literature. University of Pittsburg, 2005.

[En línea]: http:/etd.library.pitt.edu/ETD/available/etd-07122005-120122/unrestricted/seramfran040705.pdf

TAPIA, Ana María

Costumbres y tradiciones judias

Santiago, Bank Leumi, 1997.

YERUSHALMI, Yosef Hayim

Zajor: la historia judia y la memoria judia

Barcelona, Antropos Editorial; México: Fundación Cultural Eduardo Cohen, 2002. 